Article

\title{
Comparison of Unassisted and Smart Assisted Negotiation in B2B Relationships from the Perspective of Generation $Y$
}

\author{
Nikola Simkova ${ }^{1}\left(\mathbb{D}\right.$ and Zdenek Smutny ${ }^{2, *(D)}$ \\ 1 Faculty of Informatics, Masaryk University, Botanicka 68a, 60200 Brno, Czech Republic \\ 2 Faculty of Informatics and Statistics, University of Economics, Prague, W. Churchill Sq. 4, 13067 Prague 3, \\ Czech Republic \\ * Correspondence: zdenek.smutny@vse.cz
}

Received: 19 June 2019; Accepted: 15 August 2019; Published: 20 August 2019

check for updates

\begin{abstract}
The current trend in the European Union (EU) is to support the development of online dispute resolution (ODR) that saves financial and human resources. Therefore, research articles mainly deal with the design of new ODR solutions, without researching the social aspects of using different kinds of ODR solutions. For this reason, the main aim of the article is an empirical evaluation of two kinds of ODR solutions in business-to-business (B2B) relationships from the perspective of a selected social category. The article focuses on: (1) comparing unassisted and smart assisted negotiation while using the artificial intelligence approach; (2) the satisfaction and attitudes of Generation $Y$ members from the Czech and Slovak Republic towards different ways of negotiating. The conclusions of this study can help researchers to design or improve existing ODR solutions, and companies to choose the most suitable managers from Generation $\mathrm{Y}$ for B2B negotiation. The results show that Generation $Y$ members prefer computer-mediated communication as compared to face to face negotiation; the participants were more satisfied with the negotiation process when using smart assisted negotiation. Through a computer-mediated negotiation, even sellers with lower emotional stability can maintain an advantageous position. Similarly, buyers with lower agreeableness or higher extraversion can negotiate more favorable terms and offset their loss.
\end{abstract}

Keywords: artificial intelligence and law; computer-mediated communication; ICT; online dispute resolution; social informatics; out-of-court settlement

\section{Introduction}

Disputes are a problem for both business-to-consumer (B2C) and business-to-business (B2B) relationships. Particularly in the latter case, the resolution of a dispute can be stressful, time-consuming and expensive, especially when it comes to litigation [1]. However, companies have new possibilities for dispute resolution that are connected with the development of information and communication technology (ICT). Positive adoption of ICT at the personal, organizational, and social levels has created the option of alternative forms of dispute resolution. On the one hand, the aim is to reduce the burden on the courts, on the other hand, to reduce the financial burden on all parties that are involved in the dispute. There has been a growing need to address this issue online via the Internet as a result of the increase in international business and its gradual transition to digital commerce platforms-e.g., the European Commission has provided an online dispute resolution (ODR) platform since 2016 [2]. Although developed countries place great emphasis on the area of $\mathrm{B} 2 \mathrm{C}$, far greater business investment is expected in the field of B2B. According to Forrester's report [3], spending on the B2B e-commerce market should be double when compared to the B2C e-commerce market in 2019. 
ODR uses three types of negotiation: unassisted, assisted, and automated. Unassisted negotiation is usually organized freely, is flexible and, optionally, can use an email, chat, or discussion forum. There is no time limit specified and the participants can react differently regarding duration, content, and form of response [4]. Assisted negotiation uses specialized software (or platform) that defines the rules and mediates negotiation. It contributes to formulating the agenda, engaging in fruitful discussion, identifying and assessing possible solutions, as well as writing agreements [5]. This type of software also uses artificial intelligence approaches to help find the most appropriate solution [6]. The area of artificial intelligence and law (AI \& Law), which also includes assisted and automated negotiation, has been developing since 2000 .

While humans are actively involved in the two preceding ways of negotiation, automated negotiation consists mainly in the negotiation of artificial agents and the role of humans is considerably more limited. This type of negotiation is mainly used in e-commerce, where it introduces a flexible price and then maximizes the buyer's and seller's revenue [7,8]. With the development of AI (mainly soft computing approaches), automated negotiation approaches started to be applied in new topical domains in which it was not previously possible, for example, due to the high complexity of the environment, a large number of factors, or the impossibility of reducing a problem to simple formulas (e.g., simple linear equation as mentioned in [9]).

As this article deals with ODR in B2B relationships, it focuses only on unassisted and assisted negotiation, both of which are a widely accepted practice in many companies. This article is focused on computer-mediated communication via email in the case of unassisted negotiation; in the case of smart assisted negotiation an AI approach is used alongside communication rules (see Section 3 for more details).

As ODR is supported by state governments, not only in the European Union (EU) [10], research articles mainly focus on designing ICT-based solutions in the form of an artifact (e.g., method, framework, a particular software) for a particular domain [11]. Examples include the following designed solutions: Re-Consider [12], IMODRE [13], UMCourt [14], and DRExM [15]. The uniqueness of each solusion lies chiefly in the domain of use (e.g., family law; e-commerce focused mainly on C2C or B2C relationships) or the technology on which it is based (e.g., specific AI approach, process differences).

It is important to have feedback concerning their acceptance, context of use, and people's attitudes to their use to increase the success rate of the designed solutions in practice. That is why social research that focuses on the use of different kinds of ODR solutions in practice, or in conditions close to practice, is important for engineers and researchers in technology development [16]. Unfortunately, hardly any empirical research is carried out in the area of ODR. The comparison of designed artefacts e.g., [6,17] is therefore based on the description of their features and perhaps on the outcomes of their validation that was performed as part of the design cycle [16]. This situation is unsatisfactory, given the fact that a continuous and comparative evaluation "is a central and essential activity in conducting rigorous design science research" [18].

Empirical articles that are based on social research mainly focus on the social aspects that are generally associated with negotiations between people, for instance, how stress [19], language familiarity [20], cognitive workload [21] or trust in opponents [22] influence negotiation. However, such articles do not focus on negotiations that involve the use of a particular technology, nor on the social aspects associated with the use of a particular kind of solution. Thus, they do not contribute to the knowledge base regarding designed ODR solutions. Feedback is, nevertheless, very important for designers, so that they can further improve or design new ODR solutions in the form of artefacts [16].

The presented article at least partly fills this gap and, instead of pure design or social research, it focuses on social research concerning the use of particular kinds of ODR solutions and the attitudes of a selected social category to the use of these solutions. This kind of research is also significant from the analytical and normative perspective of social informatics [23], as well as the broader perspective of the social study of technology use [24]. Both perspectives make it possible to learn from the feedback that is generated by the use of a given solution. To summarize, the presented research study is important 
for designers, who design new or improve existing solutions in the form of a particular artefact. In this area, it contributes to creating the knowledge base about the sociotechnical interaction between a particular ODR solution and its users (a part of this study focuses on satisfaction with negotiations while using specific ICT-based solutions). On a practical level, the results can help companies to choose a suitable employee for B2B negotiations in the case of a dispute with another company (a part of this study focuses on the financial perspective of negotiation).

The aim of the article is to compare unassisted (UN) and smart assisted negotiation (SAN) from the perspective of their deployment at B2B level, and to present the attitude of Generation $Y$ members (from the Czech and Slovak Republic) to these two ODR approaches. The practical output of the article is a recommendation for companies indicating which of these two options of negotiation is more favorable; the recommendation also includes an assessment of the suitability of the solution in terms of the psychological profile of their managers. For this purpose, four research questions (RQ) were formulated, which took two different perspectives into account: the first area is focused on the objective and the second on the subjective aspects of negotiation.

$\mathrm{RQ}$ focusing on the financial aspect of negotiation (contributing to practice):

- RQ1: Is there a difference in the ratio of costs and benefits for the seller and the buyer, depending on the type of negotiation used (assisted and unassisted negotiation)?

- RQ2: How do the personality characteristics of the participants in the negotiation affect the results of the negotiation?

RQ focusing on the subjective aspect of satisfaction with the negotiation (contributing to the knowledge base about using selected kinds of ICT-based ODR solution):

- RQ3: How does the type of negotiation affect communication, participant behaviors and the time devoted to the negotiation?

- RQ4: How does the type of negotiation used affect satisfaction with e-negotiation and how is it evaluated compared to face to face negotiation?

The article is further divided, as follows: Description of Generation $\mathrm{Y}$ is introduced in Section 2. The methodology of the research is presented in Section 3, followed by Section 4 with the results of the study. The last section presents a discussion and conclusions of the research.

\section{Description of Generation $Y$}

Generation Y (or Millennials) is one of the largest demographic groups that is economically active and it currently affects not only the economy, but also the society and culture of individual regions. At the same time, these people are affected by the introduction of ICTs into all areas of human activity $[25,26]$. Representatives of this generation were born between the early 1980s to the late 1990s; their parents, who were born in the post-war period, belong to the Baby Boomer generation, or, if they were born in mid-1960, to Generation X [27]. However, there are some differences in how individual authors defined these periods, see the slight differences in [28-30]. The basic characteristics of this generation can be summarized in the following points [26,31]:

- This generation is closely linked to ICTs. Internet-based services (e.g., social media, online shopping, search engines) have become an ordinary part of their lives [32]. Affected by these technologies and online social connections, they approach their private and working life in a completely different way [33]. Members of this generation are also more frequently addicted to ICTs [28].

- Members of Generation Y don't prioritize money as highly as do members of Generation X, but they do prioritize fun and job flexibility. They often work from home and do not distinguish strictly between working time and family time.

- They have problems focusing on a single task because they are used to consuming many types of multimedia content and often switch their attention between them (multitasking). 
- This generation is burdened with the protective upbringing of their parents, which is reflected in their indifference and inability to accept the role of an adult in the society—see e.g., the helicopter parenting phenomenon [34]. They have a distorted view of the world, which can lead to anxiety or mental disorders [30].

- They have an instrumental approach to education. Higher education is more of a life necessity than a privilege [28].

- Companies more often focus their marketing activities on members of Generation Y, because they have become economically active and there are many of them. When choosing goods, they do not only consider the price or the primary function but also the value of the product and its appreciation in their social category.

This basic description of Generation Y members is reflected in their work skills, which include how they solve problems and interact with their colleagues [35]. The case study also included personality tests for the participants from Generation $Y$, in order to understand their personality and emotional status, see Section 3.

\section{Methods and Data Collection}

The embedded single-case design was chosen for conducting case study research with twenty embedded units according to [36]. This qualitative research has fewer case study participants when compared to the number of respondents in quantitative research, but it is balanced by a deeper insight into the issue [37]. In the case study, 40 students assumed the role of company managers who buy or sell their goods to foreign partners. Two thematically different negotiating situations were created (A and B). Each situation was realized in 10 case study units: five units with SAN and five units with UN. Each of these 5 units had a different number of products $(3,4,5,6$ and 7$)$, which were delivered in insufficient quantity or quality from the seller to the buyer. The different numbers of defective products were used in order to show whether there were any differences in negotiation as the complexity of the scenario increased. These goods or products were the subject of a dispute that had to be negotiated. The seller-buyer pair consisted of one student from the Czech Republic and one student from the Slovak Republic to simulate international negotiation, which is typical for B2B relationships. Altogether, ten case study units were focused on SAN and the other ten on UN.

A third-party web application, which is available at http://comp.se/e-negotiation, was developed to facilitate data collection. Each participant obtained an email with instructions and login data for that interface. The process of the case study is shown in Figure 1. Before starting the negotiations, participants were asked to fill in a questionnaire to provide basic demographic information, information about their personality characteristics based on the Ten Item Personality Inventory (TIPI) [38], and about their emotions, while using the Positive and Negative Affect Schedule (PANAS) [39]. To identify the values of the five dimensions of personality (extraversion, agreeableness, conscientiousness, emotional stability, and openness), the participants were asked to which extent they agree or disagree with 10 statements on a seven-point scale (1-Disagree strongly, 7-Agree strongly). To determine the positive and negative affects, participants were asked to rate the extent to which they experienced each of the 20 emotions on a 5 point scale (1-Very slightly, 5 -Very much). The values that were obtained for TIPI must be in the range of 1-7 and for PANAS 10-50. A high score indicates the presence of an intense positive/negative affect [40]. After completing the questionnaire, the students returned to the web interface, where they gathered initial information for negotiation and proposed possible solutions.

In the case of the UN, the participants received the email address of their business partner and the negotiation continued as an exchange of email correspondence between the two parties as long as it took for both sides to agree on one solution. In the case of SAN, the negotiation was conducted according to a method [41], which uses a genetic algorithm to recommend the most appropriate solution. For this purpose, an application was developed that implemented the proposed genetic algorithm. Once each of the negotiating parties had proposed a solution to the dispute, these suggestions were used as the inputs to the genetic algorithm (heuristic approach), which subsequently proposed an optimal 
or quasi-optimal solution. The resulting solution was then offered to both parties. The negotiation was terminated if both parties agreed that the solution was suitable for them. If one of the parties did not agree, a second iteration of the negotiation started. After carrying out the case study, all of the participants returned to the web interface and completed a questionnaire, where they subjectively evaluated the negotiation process.

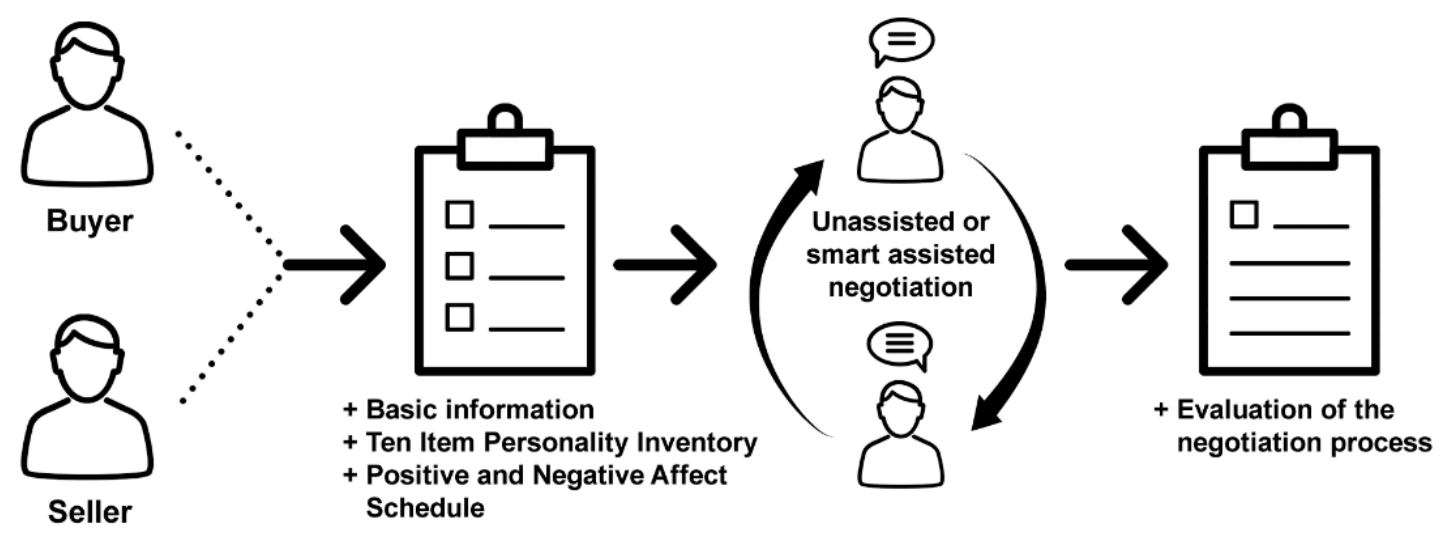

Figure 1. The case study process with twenty embedded units.

The case study participants did not know each other before the negotiations began. They were students who attended two courses at a university of economics, one in the Czech Republic and one in the Slovak Republic. All communication that was part of the negotiation was monitored and the case study process was taken into account when students were evaluated within their courses. The students were evaluated according to their level of engagement or activity in the case study, rather than on the basis of the results that they achieved in the negotiation. The research lasted a month, due to the high number of iterations during the negotiation and due to a communication delay, because the students had to respond within three days. The participants were informed of this restriction at the beginning of the research, which was to prevent inflexible communication. The implicit limitations of the research are its focus only on members of Generation $Y$ and the fact that case study participants come from the Czech and the Slovak Republic, i.e., the Central European region.

The data that were obtained from research were analyzed through the Clementine 11.1 SPSS software, while using the $\mathrm{C} 5.0$ algorithm to create the decision trees and rules. These data mining techniques are suitable for research due to their clarity and ease of interpretation.

\section{Results}

The results of the embedded single case study are divided into the objective and subjective point of view. In an objective view, compensations were expressed in monetary value according to the negotiation between the buyer and the seller. This helped to calculate the ratios of costs and benefits for the seller and the buyer. Moreover, the characteristics of the buyer or seller influence these relative indicators were analyzed. The subjective aspect reflects the evaluation of the negotiation by participants regarding negotiation time, satisfaction with the used approach (UN or SAN), communication, and business partner behavior. In addition, the participants assessed their satisfaction with computer-mediated negotiation compared to face to face negotiation. Both of these approaches to negotiation (UN and SAN) are in the following text referred to as e-negotiation, because they are computer-mediated communication.

\subsection{Financial Perspective of Negotiation}

All of the agreements were analyzed from a financial point of view. The solution for each product was expressed in money; the sum expresses the total compensation. It is important to realize that the case study moves in different financial ranges, which is why, instead of absolute results, relative 
indicators (a ratio of costs and benefits) were chosen. They are only related to the value of the defective goods, i.e., goods that were delivered in insufficient quantity or quality.

The costs in the event of a dispute represent for the seller the sum of the cost of producing the defective goods and the total compensation, his or her benefits are the sale price received from the buyer. Production costs are costs in the event of a dispute related to defective goods (as in this research). They were spent, but the goods did not meet the required characteristics. The sale price is calculated according to the costs of production; their difference means a profit (loss) for the seller. The compensation that is payable by the seller in the event of a dispute will increase his or her costs. The graph (Figure 2) shows the ratio of costs and benefits for the seller according to the case study units (the letters A/B mean two negotiating situations, while the number 3/4/5/6/7 represents the number of products in the negotiation) and the negotiation type (SAN and UN). Ideally, if the ratio does not exceed 1, the costs are not greater than the benefits. As can be seen, this happened in half of the negotiations, equally for SAN and UN. The influence of the negotiation type used is not confirmed.

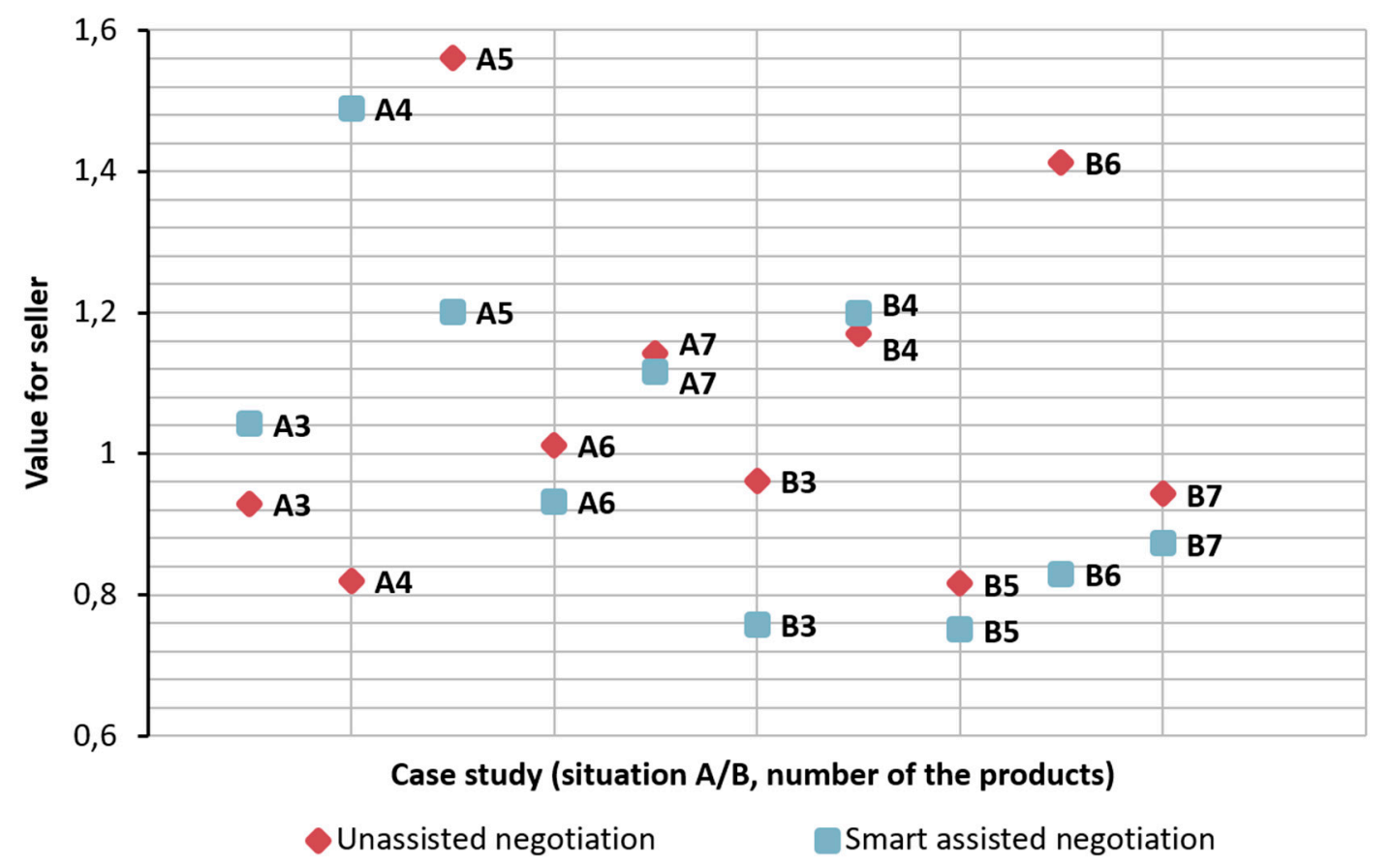

Figure 2. The ratio of costs and benefits for the seller.

The ratio of costs and benefits can also be monitored from the buyer's position (Figure 3). The costs represent the total sale price paid by the buyer for defective goods. The benefits represent the estimated loss to the buyer if he or she does not agree with the seller, depending on the price at which the buyer sells the goods to his or her customers. The estimated loss means saved funds that the buyer will incur if he or she successfully agrees with the seller (all the pairs agreed in this research, thus it makes sense to incorporate it into the buyer's benefits). The agreed compensation is also added to the benefits if the value is positive for the buyer. Costs should not exceed benefits, thus the ratio should not exceed 1. The increase occurs in two case study units: four products in situation A with UN and five products in situation B via SAN. Again, the values of relative indicators are fairly balanced for both negotiation types.

Based on the results, RQ1 can be answered: Is there a difference in the ratio of costs and benefits for the seller and the buyer, depending on the type of negotiation used (assisted and unassisted negotiation)? 


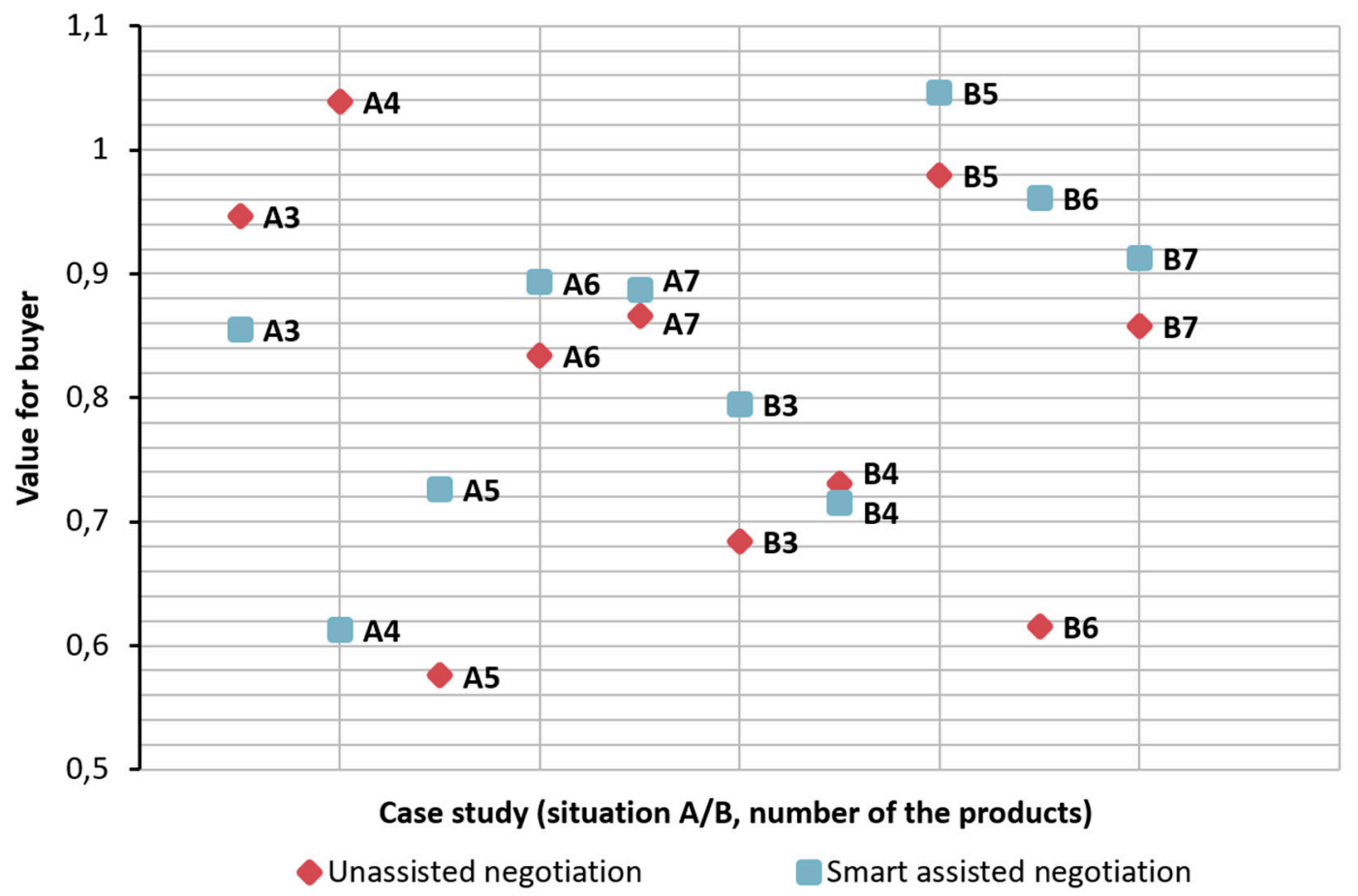

Figure 3. The ratio of costs and benefits for the buyer.

As seen in Figures 2 and 3, the relative indicator values are relatively balanced for both negotiation types, therefore it cannot be confirmed that there is a difference between them according to the negotiation type used. SAN and UN do not cause significant differences in the ratio of costs and benefits, either for the seller or the buyer. While the costs for the buyer exceeded the benefits in two cases, for the seller it happened in half of the negotiations. It is understandable that the additional costs in the form of compensation arise on his or her part, given the fact that the dispute was caused by the seller's failure.

It was considered how the characteristics of the buyer or seller-age, sex, country of study, five factors of personality (extraversion, agreeableness, conscientiousness, emotional stability, and openness), positive and negative affects (values are described in Section 3)-influences the relative indicators. If negotiation type was added as the input, the results did not change, even with one decision tree; therefore the method does not affect the results.

The ratio of costs and benefits for the seller was divided into four groups, depending on the value that they acquire. Using the $\mathrm{C} 5.0$ algorithm, a decision tree with $85 \%$ confidence (Appendix A) and seven decision rules with $90 \%$ confidence were obtained:

1. rule: if a person has emotional stability less than or equal to 3.5 , then the ratio is less than or equal to 0.85 (Instance: 3 , Confidence: 0.8 );

2. rule: if a person is female, then the ratio is less than or equal to 0.85 (I: 8, C: 0.85);

3. rule: if a person has emotional stability greater than 5.5 and an openness of less than or equal to 5.5 , then the ratio is less than or equal to 1 (I: 3, C: 0.8 );

4. rule: if a person has a negative affectivity of less than or equal to 22 , and she is a woman with emotional stability greater than 4 , then the ratio is less than or equal to 1 (I: 2, C: 0.75 );

5. rule: if a person has emotional stability from 3.5 to 4 inclusive, then the ratio is less than or equal to 1.15 (I: 2, C: 0.75);

6. rule: if a person has emotional stability and openness above the value of 5.5 , then the ratio is greater than 1.15 (I: 3, C: 0.8); and,

7. rule: if a person has emotional stability greater than 4 , then the ratio is greater than 1.15 (I: 15 , C: 0.412$)$. 
Subsequently, a relative indicator was analyzed for the buyer, which was divided into four intervals. The result was a decision tree (Appendix B) and six decision rules, with 90\% confidence:

1. rule: if a person has agreeableness of less than or equal to 4 , then the ratio is less than or equal to 0.75 (I: 5, C: 0.857);

2. rule: if a person's extraversion exceeds 3.5 , then the ratio is less than or equal to 0.75 (I: 4, C: 0.667 );

3. rule: if a person has agreeableness greater than 4, emotional stability greater than 6 and studies in the Czech Republic, then the ratio is less than or equal to 0.9 (I: 3, C: 0.8 );

4. rule: if a person exhibits a negative affectivity less than or equal to 14 and has agreeableness greater than 4 , then the ratio is less than or equal to 0.9 (I: 3, C: 0.8 );

5. rule: if a person has agreeableness greater than 4 , emotional stability less than or equal to 6 , studies in the Czech Republic, and is younger than 24 years old, then the ratio is less than or equal to 1 (I: 3, C: 0.8); and,

6. rule: if a person exhibits negative affectivity greater than 14, their extraversion is less than or equal to 3.5 and they study in the Slovak Republic, then the ratio is greater than 1 (I: 3, C: 0.6).

Based on the results, it is possible to respond to RQ2: How do the personality characteristics of the participants in the negotiation affect the results of the negotiation?

For the seller, other personality characteristics (emotional stability, sex) are significant than for the buyer (agreeableness, extraversion). A lower level $(\leq 3.5)$ of emotional stability in a seller results in a lower level $(\leq 0.85)$ of the relative indicator (a ratio of costs and benefits), while a seller with higher emotional stability $(>4)$ obtains the highest value $(>1.15)$ of the relative indicator. Paradoxically, a seller who is less emotionally stable (more anxious and easily upset) achieves a lower ratio of costs and benefits (which is desirable) through e-negotiation (UN and SAN together). This affirms that e-negotiation helps participants with low emotional stability to resolve the dispute. This aspect appeals to the seller; the dispute may affect his or her reputation and future cooperation with the business partner, because reputation is one of the most important parts of the image of a company [42]. It turns out that e-negotiation is more suitable for women, because they have a lower level $(\leq 0.85)$ of the ratio of costs and benefits.

Several studies [43-47] claim that, whereas men communicate in a direct, loud, confrontational way, women tend to communicate in an indirect way and find it difficult to express themselves freely and directly in a face to face communication. Therefore, women may experience less social recognition, which may stimulate or increase the intensity of their online communication [48] and their preference for and frequency of using for example text messaging and social media when compared to men [49]. Cultural identity is shown as a relevant factor for the buyer. Slovak students with a lower level of extraversion $(\leq 3.5)$ and a higher negative affectivity $(>14)$ get worse negotiation results-a higher ratio of costs and benefits $(>1)$. If the buyer has a lower level of agreeableness $(\leq 4)$, this is reflected in a lower ratio $(\leq 0.75)$ of costs and benefits. This means that, when the buyer is more critical and quarrelsome, he or she negotiates better conditions. The same situation occurs if a person has a higher extraversion (>3.5). A more extraverted and enthusiastic buyer can negotiate more favorable conditions.

\subsection{Subjective Aspect of Satisfaction with the Negotiation and Its Results}

The analysis is based on information from the final questionnaire, in which the participants had the opportunity to assess the negotiation and its results. They were asked to estimate the total net time devoted to the case study. As can be seen from the graphs (Figure 4), almost half of the participants ( $47.5 \%$ ) handled the case study in 2 to $3 \mathrm{~h}$; two-thirds negotiated with UN. Time slots "from 1 to $2 \mathrm{~h}$ " and "from 3 to $4 \mathrm{~h}$ " were other possible periods that students marked as the time devoted to the case study. Two participants were able to complete the case study within $1 \mathrm{~h}$. Both used SAN to negotiate about four or six products. One participant spent more than $6 \mathrm{~h}$ on the case study, which involved a renegotiation of seven products because the pair did not agree after the first iteration. 

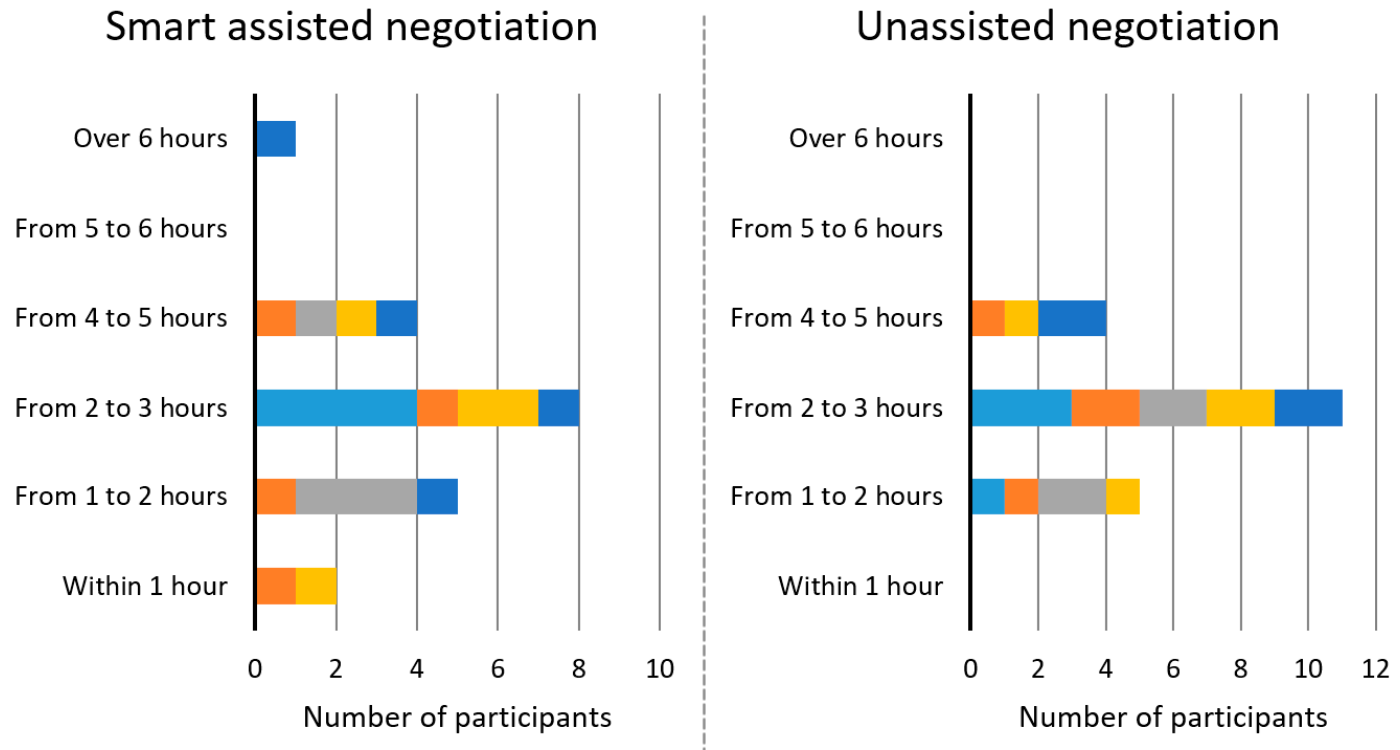

$\varpi 3$ products $₫ 4$ products $₫ 5$ products $₫ 6$ products $\square 7$ products

Figure 4. Total net time devoted to the case study.

For each item, the participants added the degree to which they agreed with the statement based on their experience of the case study. The scale ranged from 1 (Disagree strongly) to 7 (Agree strongly).

Communication plays an important role in negotiation. In other questions regarding communication, the students were divided according to the negotiation type they used (Appendix C). Students negotiating via UN expressed greater consensus with the statements about communication, when compared to students negotiating through SAN. Participants negotiating via UN could react quickly and easily to the partner, express their feelings and views, understand the feelings and views of their partner, and convince the partner to accept their offers.

The final questionnaire also looked at the behavior of the business partner in the negotiation (Figure 5). Most of the participants agreed that their partner was friendly. When negotiating via UN, it was 10\% more than through SAN. Two-thirds of the participants agreed with the statement that their partner reiterated their concessions (independent on the negotiation type used).
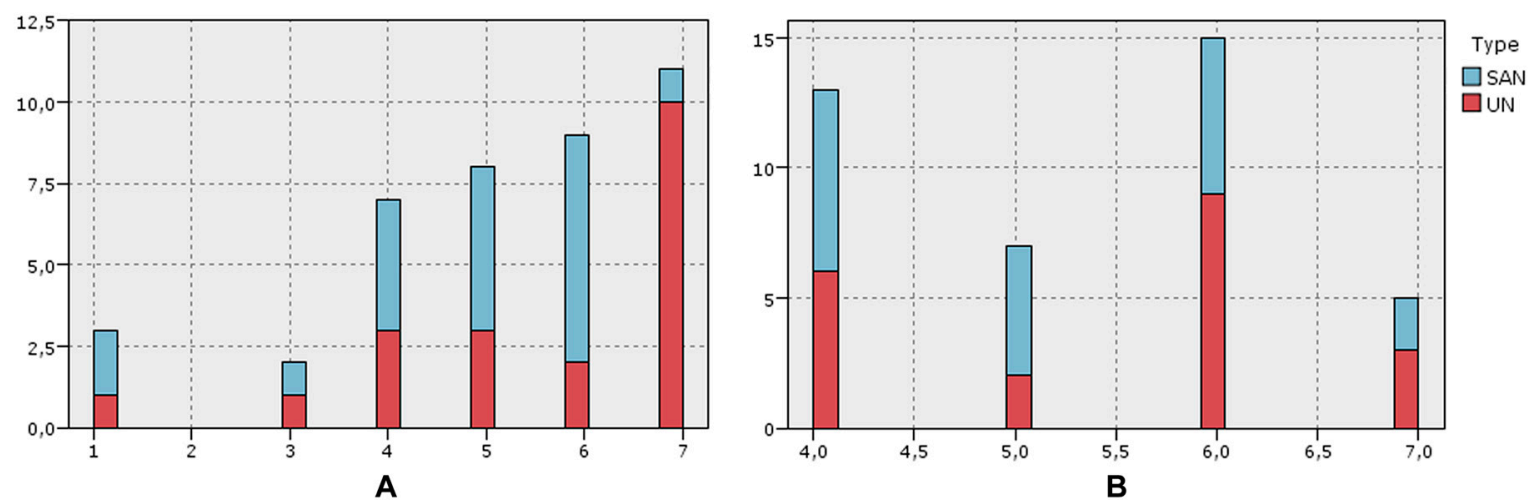

Figure 5. The partner behavior. $\mathrm{UN}=$ unassisted negotiation; $\mathrm{SAN}=$ smart assisted negotiation; $\mathrm{A}=$ My partner was friendly with me during the negotiation; $\mathrm{B}=$ My partner also made a concession if I had made a concession.

Based on the results, it is possible to respond to RQ3: How does the type of negotiation affect communication, participant behaviors, and the time devoted to the negotiation? 
Except for the case that involved renegotiating seven products, the participants devoted less time to the case study when they negotiated with SAN than via UN. It turns out that SAN brings time savings when compared to the situation where the participants negotiate between themselves without assistance.

Participants who negotiated through UN agreed more with the statements that they could respond quickly and easily to the partner, express their feelings and views, understand the feelings and views of their partner, and persuade a partner to accept their offers. The results of this assessment might be related to the fact that in the case of private communication without assistance, the partners came into contact, and the response from their partner came to their email address, while in the case of SAN, the participants communicated with the application that displayed reactions from their partner, but they did not directly communicate with him or her. However, the assessment of quick reaction for $\mathrm{UN}$ is relative, because the total net time devoted to the case study is higher than for SAN. The participants did not experience both types of negotiation, therefore they could not compare reaction speed. Communication between partners for SAN only took place within the application, which also helped to reduce time. Moreover, the genetic algorithm offered possible alternatives for dispute resolution, which saved the participants time.

There was no difference between the negotiation types used when evaluating the return of the partner's concession. A difference emerged when assessing the business partner's behavior. Agreement with the statement that their partner was friendly was expressed by $10 \%$ more participants while using $\mathrm{UN}$ than in the case of SAN. It may again be related to the fact that communication was only between participants without assistance.

The participants, in their preparation for a future managerial position, have already experienced face to face negotiation, and they were asked to compare these two approaches. They rated their satisfaction with the negotiation process that they experienced during the case study ranging from 1 (Very dissatisfied) to 7 (Very satisfied). The graph (Figure 6) shows that $90 \%$ of the participants who used SAN were satisfied with the e-negotiation process (values above 5 inclusive). $75 \%$ of students were satisfied in the case of UN.

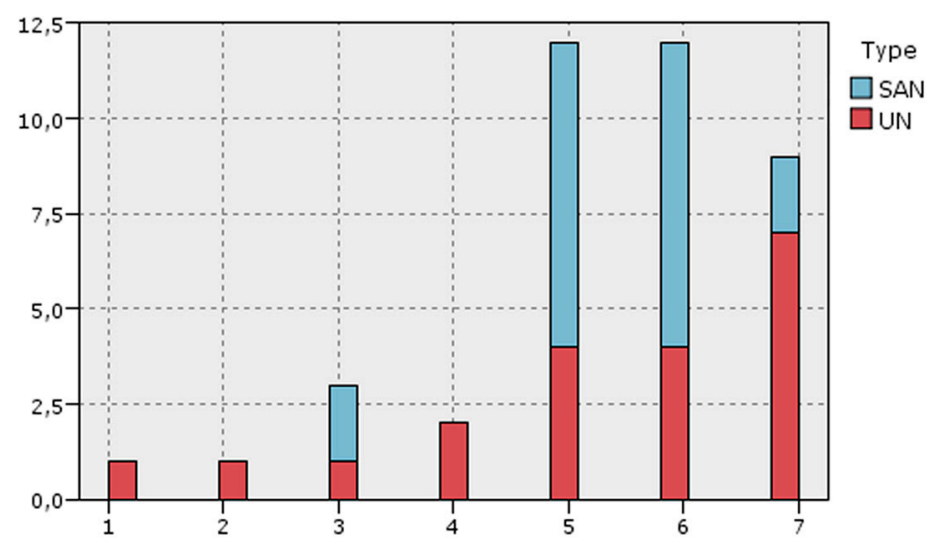

Figure 6. Participants' satisfaction with the negotiation process that they experienced during the case study. $\mathrm{UN}=$ unassisted negotiation; $\mathrm{SAN}=$ smart assisted negotiation.

The questionnaire also included open questions, in which participants were asked to indicate what positives and negatives they see in e-negotiation as opposed to face to face negotiations. The table (Table 1) lists the benefits of e-negotiation. The most frequently cited advantage is the possibility of distance negotiation, which provides time flexibility. There is also the possibility of depersonalization, along with the possibility of longer thinking. A quarter of the participants assessed saving money as positive. 
Table 1. Positives of e-negotiation.

\begin{tabular}{ccc}
\hline Positives of E-Negotiation Compared to Face to Face Negotiation & Count & Percent \\
\hline There is no need to meet, match time (remote negotiation with custom time arrangement) & 15 & $38 \%$ \\
Less personal & 13 & $33 \%$ \\
There is no need to react quickly (the possibility to think about one's proposal) & 13 & $33 \%$ \\
Money saving & 10 & $25 \%$ \\
Proportionally fast proposal and evaluation & 4 & $10 \%$ \\
Transparency of negotiation & 3 & $8 \%$ \\
Objectivity & 1 & $3 \%$ \\
\hline
\end{tabular}

The most frequently mentioned disadvantage of e-negotiation was the absence of personal contact $(60 \%)$. Another negative was the prolongation of negotiation due to a partner's late reactions. A lower willingness to compromise was identified as a difficulty, as can be seen from the table (Table 2).

Table 2. Negatives of e-negotiation.

\begin{tabular}{ccc}
\hline Negatives of E-Negotiation Compared to Face to Face Negotiation & Count & Percent \\
\hline Missing human (personal) contact (absence of emotions) & 24 & $60 \%$ \\
Prolongation of communication (if the other party does not respond immediately; in case & 17 & $43 \%$ \\
of disagreement) & 4 & $10 \%$ \\
Waiting for response & 1 & $3 \%$ \\
Lower willingness to compromise & 1 & $3 \%$ \\
Occasional confusion in communication & 1 \\
\hline
\end{tabular}

Participants using SAN who were dissatisfied with the process mainly saw negatives in the time horizon-waiting for a partner's response. For one participant, the time that was devoted to the case study (over $6 \mathrm{~h}$ ) could be reflected in his or her (dis)satisfaction with the process.

Based on the results, it is possible to respond to RQ4: How does the type of negotiation used affect satisfaction with e-negotiation and how is it evaluated compared to face to face negotiation?

Participants negotiating with SAN were more satisfied with the e-negotiation process $(90 \%)$ than the students negotiating through UN (75\%) if they compared e-negotiation to face to face negotiation. All participants, regardless of the type of negotiation used, expressed greater satisfaction with e-negotiation when compared to face to face negotiation. They mentioned benefits, such as distance negotiation, depersonalization, longer thinking, and money saving. On the other hand, the disadvantages of e-negotiation were the absence of personal contact, the possible extension of negotiation time due to late partner reactions, and the lower willingness to compromise. Paradoxically, the lack of human contact and possible later responses belong to the positive as well as negative side of e-negotiation. The preference for a communication style based on gender (men tend to communicate in a direct way, while women use an indirect one) was mentioned in Section 4.1. Moreover, the participants took into account that the case study focused on B2B relationships, where speed is important as well as establishing good relationships between business partners.

\section{Discussion and Conclusions}

In addition to making phone calls and writing letters, face to face negotiation was the primary approach that was used in negotiation before the adoption of modern ICT in everyday life. Generation $\mathrm{Y}$ is closely linked with ICT, which is also shown in their preference of e-negotiation, in which they feel more satisfied with the possibility of distance negotiation, depersonalization, longer thinking, and money savings. The participants were even more satisfied with the negotiation process when using SAN.

Although two technologically different ways of negotiation were used in the study (UN via email vs. SAN using a genetic algorithm), the differences between them were not observed in the ratio of costs and benefits (for seller and buyer). The costs exceed over the benefits more often on 
the seller side, which is related to the assumption that the dispute was caused by the seller's error. On the other hand, there are differences between the methods in the participants' evaluation of the negotiation process. The respondents spent less time on the case study in the case of SAN. However, communication and the accommodating behavior of the partner was evaluated more positively by participants negotiating via email (UN). New technologies and approaches offer time savings in negotiation, but participants' evaluation might be more neutral in the area of communication and partner behavior, because new technologies may seem like a barrier between them. This barrier may be beneficial in the case of a significant emotional disturbance and stress that managers can suffer in practice. The study confirms that e-negotiation helps to solve the dispute if the participants are emotionally involved. Assisted or unassisted computer-mediated negotiation is suitable for women who are weaker in face to face communication.

The seller was the cause of the dispute in this study and the buyer suffered damage. Companies may find useful the finding that a seller who was more anxious and easily upset managed to maintain an advantageous position (costs did not exceed benefits even after the compensation was paid). On the other hand, a buyer who has a lower agreeableness (more critical and quarrelsome) or higher extraversion (more extraverted and enthusiastic) can negotiate more favorable terms and offset the loss that is caused by the seller's error.

The case study that was carried out differ in the number of products, which created differences in the complexity of the task. Decision making is more demanding with a larger number of products, as was shown in the repeated SAN with seven products. When the number of products was five or more, the seller achieved a lower ratio of costs and benefits in the case of SAN-the seller negotiated conditions that increased costs to a lesser extent than in the case of UN. On the other hand, the buyer negotiated higher compensation in the case of UN for five or more products.

The participants in this research were randomly assigned to the negotiation pairs and, after that, the personal characteristics were obtained. In subsequent research, the personality of the participant could be assessed first and the pairs created on that basis. This approach could result in different and interesting combinations of people in pairs for negotiation and it could be a suggestion for further research.

Promoting access to efficient and effective redress mechanisms through alternative dispute resolution procedures has been identified as a way to achieve the goal of the European Commission's Digital Single Market strategy [50]. As the European Commission stated in its report on the functioning of the European ODR platform [50]: “It will be essential to improve traders' engagement, so as to ensure that the complaints that cannot be settled bilaterally (i.e., outside of the platform or through traders' internal complaint systems) are effectively channeled through the ODR platform". However, the EU communication activities that further promote the ODR platform enhance the awareness of companies in this area. The European ODR platform only facilitates communication between disputing parties (exchange of information), whereby the trader can negotiate with the consumer or the dispute can be moved to an alternative dispute resolution body and use other ODR methods than negotiation. However, the platform does not offer SAN, which could be an alternative to UN for dispute parties. As shown in this study, SAN provides time savings when compared to a situation where the participants negotiate without assistance. Especially for Generation Y members, who see ICT as part of their lives, SAN can provide a more convenient approach to settling a dispute (clear communication rules definition) than uncoordinated email negotiation.

It must be added that the ODR field is still evolving, and individual ODR initiatives in the world progressively solve the identified weaknesses of designed solutions. The most common issues are related to the social component of ODR systems [51], or questions of quality, ethics, practitioner training, service provider qualifications, monitoring [52], and data protection [53]. 
Author Contributions: N.S. carried out part of the case study in the Slovak Republic and prepared the statistical analysis. Z.S. carried out part of the case study in the Czech Republic and programmed application for smart assisted negotiation, which uses the genetic algorithm to recommend the most appropriate solution. Both authors together defined the methodology and formulated research questions. The manuscript was written equally together.

Funding: This research was funded by University of Economics, Prague, grant number F4/1/2019.

Conflicts of Interest: The authors declare no conflict of interest.

\section{Appendix A}

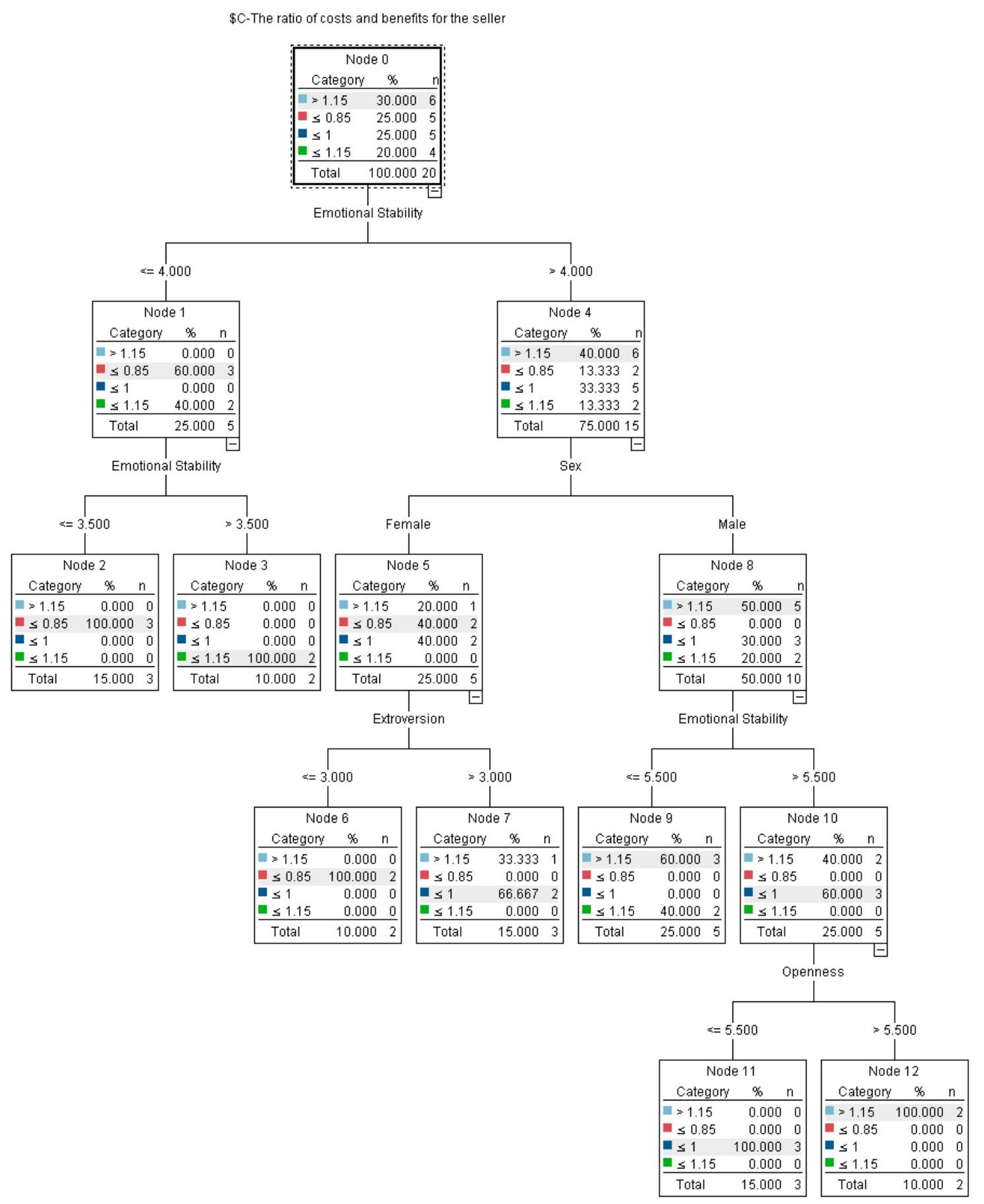

Figure A1. Decision tree for seller. 


\section{Appendix B}

$\$ \mathrm{C}$-The ratio of costs and benefits for the buyer

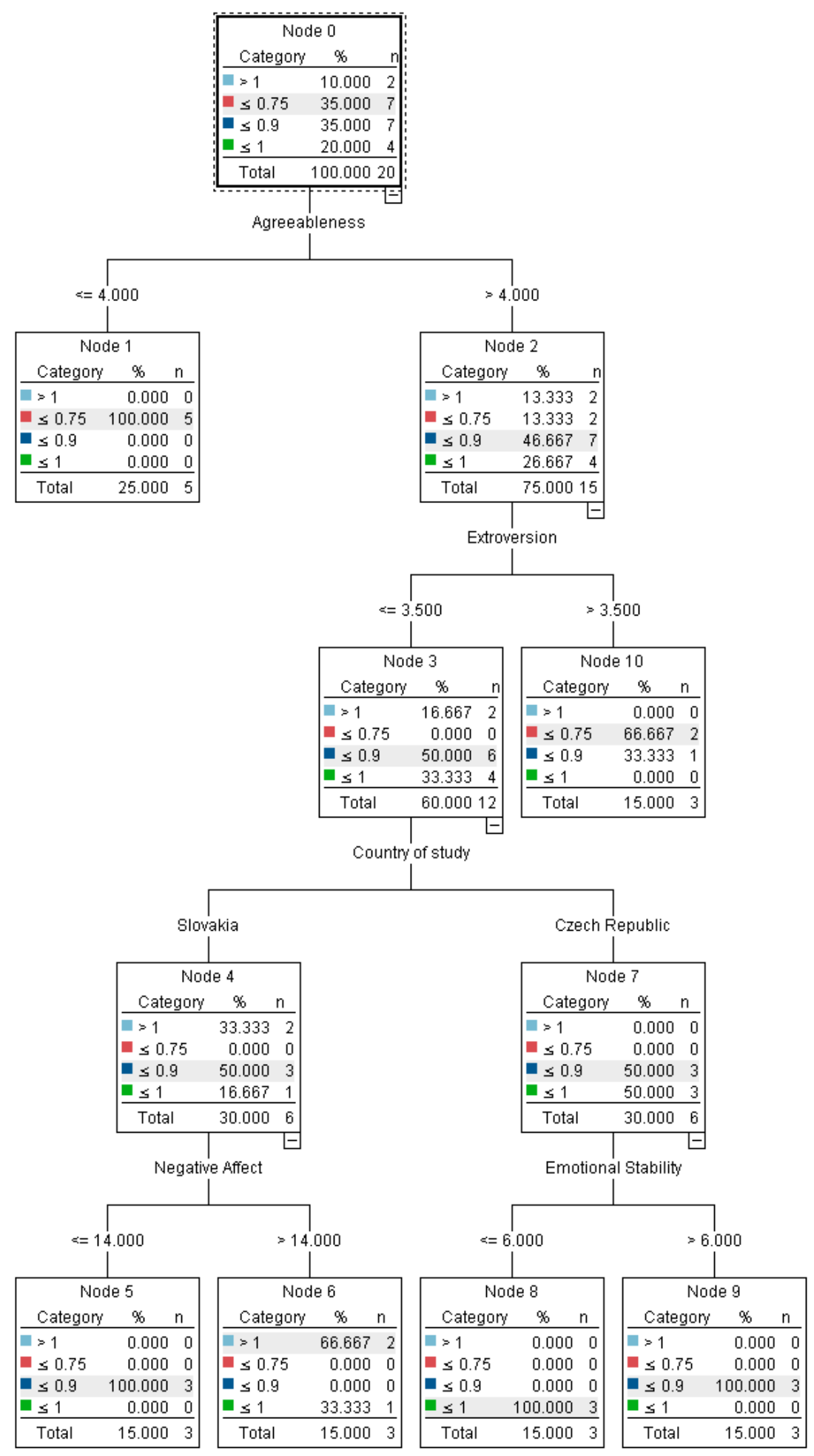

Figure A2. Decision tree for buyer. 


\section{Appendix C}

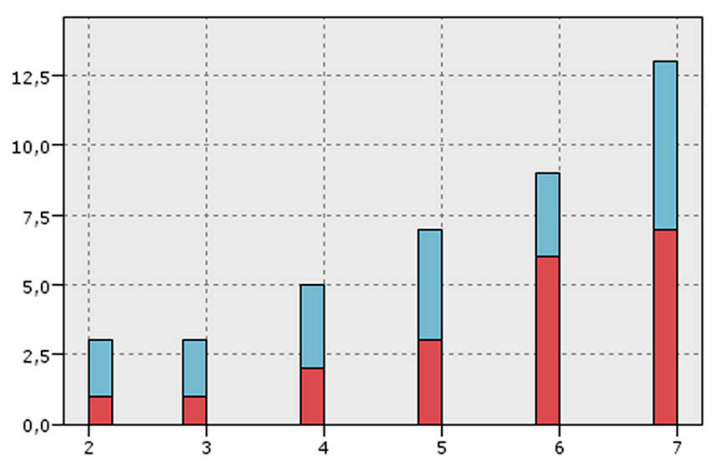

A
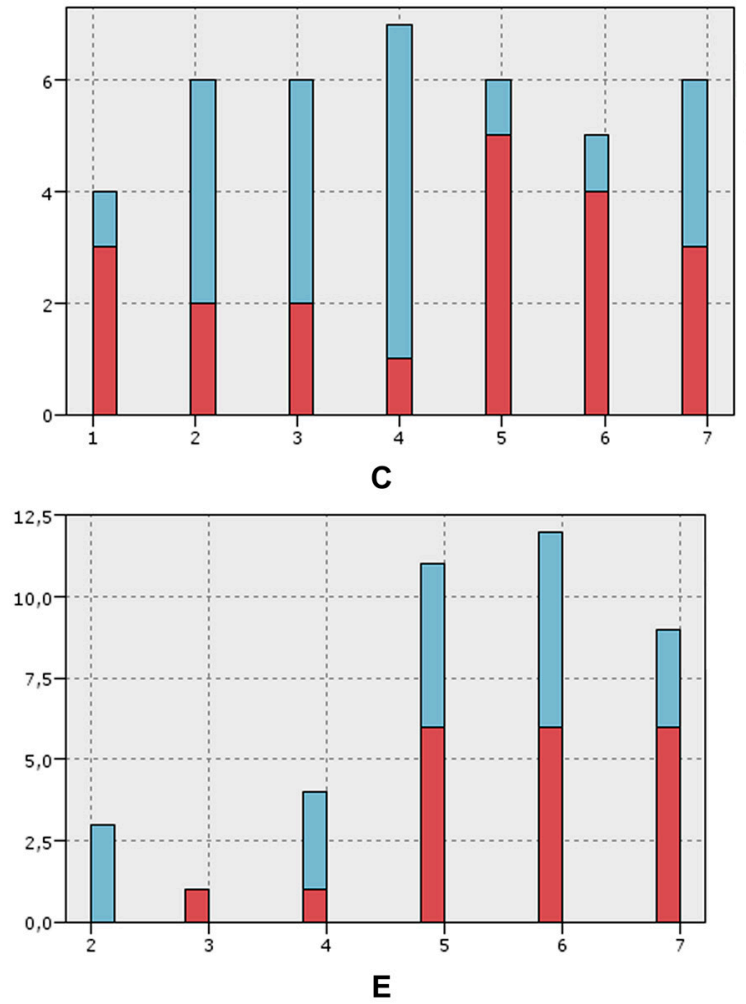
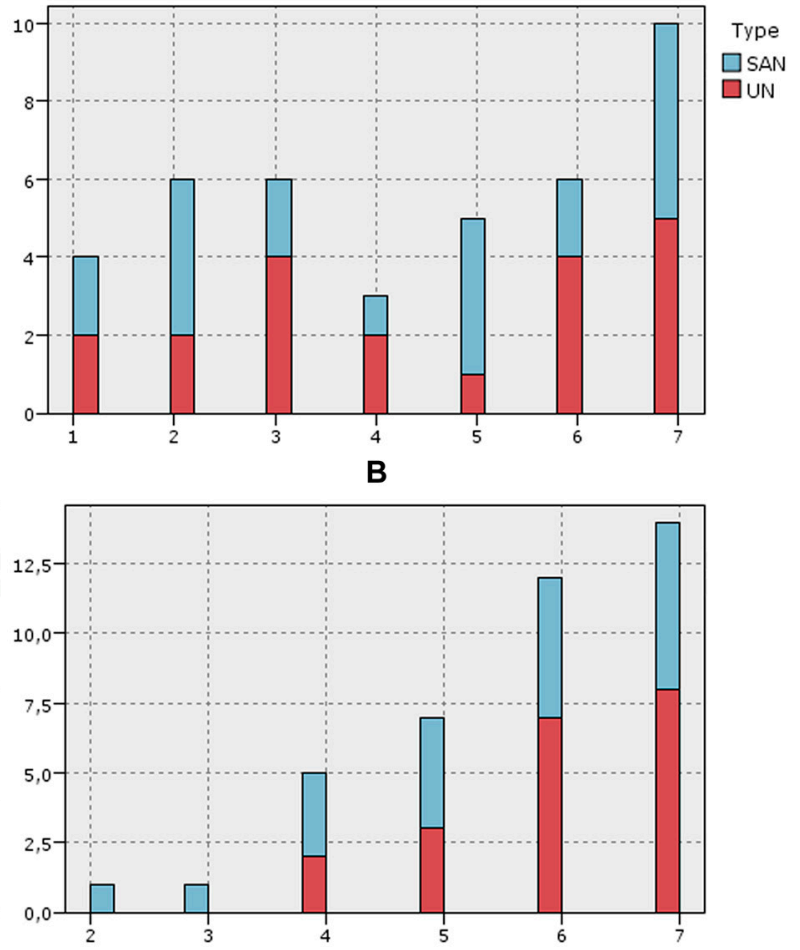

D

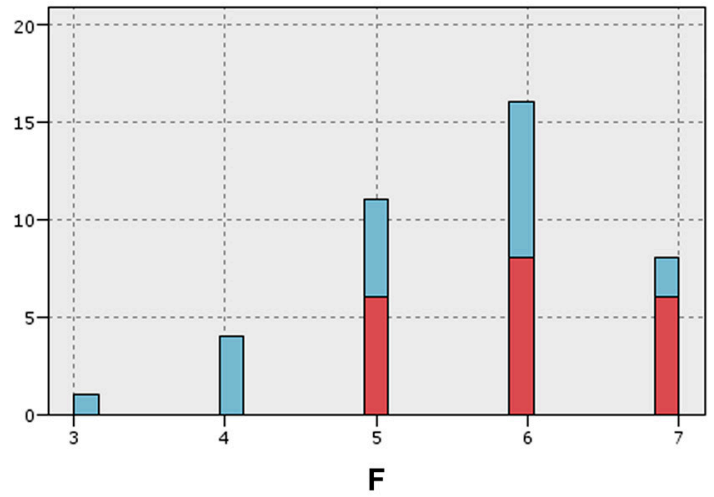

Figure A3. Communication with partner. $\mathrm{UN}=$ unassisted negotiation; $\mathrm{SAN}=$ smart assisted negotiation; A = I could react quickly and easily to my partner during the negotiation.; B = I could quickly and easily express my feelings during the negotiation.; $\mathrm{C}=\mathrm{I}$ could quickly and easily understand my partner's feelings during the negotiation.; $\mathrm{D}=\mathrm{I}$ was able to express my views correctly during this negotiation.; $\mathrm{E}=\mathrm{I}$ could understand the views of my partner correctly during this negotiation.; $\mathrm{F}=\mathrm{I}$ convinced my partner to accept my offers.

\section{References}

1. Lu, Z.M.; Zhu, X.Y. Study on the Online Dispute Resolution System in China. In Proceedings of the 6th International Conference on Energy, Environment and Sustainable Development, Phuket, Thailand, 11-12 March 2017; Atlantis Press: Paris, France, 2017; pp. 360-367.

2. EU ODR. Online Dispute Resolution: Resolve Your Online Consumer Problem Fairly and Efficiently without Going to Court. Available online: https://ec.europa.eu/consumers/odr/ (accessed on 19 June 2019).

3. Columbus, L. Predicting the Future of B2B E-Commerce. Available online: https://www.forbes.com/sites/ louiscolumbus/2016/09/12/predicting-the-future-of-b2b-e-commerce (accessed on 19 June 2019).

4. Tang, Z. An effective dispute resolution system for electronic consumer contracts. Comput. Law Secur. Rev. 2007, 23, 42-52. [CrossRef] 
5. Schultz, T.; Kaufmann-Kohle, G.; Langer, D.; Bonnet, V. Online Dispute Resolution: The State of the Art and the Issues; University of Geneva: Geneva, Switzerland, 2001; Available online: https://ssrn.com/abstract=899079 (accessed on 19 June 2019).

6. Carneiro, D.; Novais, P.; Andrade, F.; Zeleznikow, J.; Neves, J. Online dispute resolution: An artificial intelligence perspective. Artif. Intell. Rev. 2014, 41, 211-240. [CrossRef]

7. Kexing, L. A Survey of Agent Based Automated Negotiation. In Proceedings of the International Conference on Network Computing and Information Security, Guilin, China, 14-15 May 2011; IEEE: New York, NY, USA, 2011. [CrossRef]

8. Syed, T.Q.; Khan, B.; Shams, F.; Khan, M.F.; Behlim, S.I.; Khatoon, H.; Shaikh, Z. A robust strategy for automated negotiations. Multiagent Grid Syst. 2017, 13,1-17. [CrossRef]

9. De Jonge, D.; Sierra, C. D-Brane: A diplomacy playing agent for automated negotiations research. Appl. Intell. 2017, 47, 158-177. [CrossRef]

10. Dafna, L. Three is not a crowd: Online mediation-arbitration in business to consumer internet disputes. Univ. Pa. J. Int. Law 2016, 37, 871-941.

11. Omoola, S.O.; Oseni, U.A. Towards an Effective Legal Framework for Online Dispute Resolution in E-commerce Transactions: Trends, Traditions and Transitions. IIUM Law J. 2016, 24, 259-281. [CrossRef]

12. Muecke, N.; Stranieri, A.; Miller, C. Re-consider: The integration of online dispute resolution and decision support systems. In Proceedings of the CEUR Workshop Proceedings of the 5th International Workshop on Online Dispute Resolution, Firenze, Italy, 13 December 2008; pp. 62-72.

13. Abrahams, B.; Belluci, E.; Zeleznikow, J. Incorporating Fairness into Development of an Integrated Multi-agent Online Dispute Resolution Environment. Group Decis. Negot. 2012, 21, 3-28. [CrossRef]

14. Carneiro, D.; Novais, P.; Andrade, F.; Zeleznikow, J.; Neves, J. Using Case-Based Reasoning and Principled Negotiation to provide decision support for dispute resolution. Knowl. Inf. Syst. 2013, 36, 789-826. [CrossRef]

15. Elziny, A.A.; Mohamadien, M.A.; Ibrahim, H.M.; Abdel Fattah, M.K. An expert system to manage dispute resolutions in construction projects in Egypt. Ain Shams Eng. J. 2016, 7, 57-71. [CrossRef]

16. Wieringa, R.J. Design Science Methodology for Information Systems and Software Engineering; Springer: New York, NY, USA, 2014. [CrossRef]

17. Orji, U.J. Technology Mediated Dispute Resolution: Challenges and Opportunities for Dispute Resolution in Nigeria. Comput. Telecommun. Law Rev. 2012, 18, 124-134.

18. Venable, J.; Pries-Heje, J.; Baskerville, R. A Comprehensive Framework for Evaluation in Design Science Research. In Proceedings of the International Conference on Design Science Research in Information Systems, Las Vegas, NV, USA, 14-15 May 2012; Springer: Berlin/Heidelberg, Germany, 2012; pp. 423-438. [CrossRef]

19. Gomes, M.; Oliveira, T.; Carneiro, D.; Novais, P.; Neves, J. Studying the effects of stress on negotiation behavior. Cybern. Syst. 2014, 45, 279-291. [CrossRef]

20. Lai, H.; Lin, W.-J.; Kersten, G.E. The importance of language familiarity in global business e-negotiation. Electron. Commer. Res. Appl. 2010, 9, 537-548. [CrossRef]

21. De Moura, J.A.; França, S.D.; Daher, D.; Cabral, A.P.; Costa, S. Using psychophysiological data to investigate differences by gender and negotiation styles in e-negotiation. In Proceedings of the IEEE International Conference on Systems, Man, and Cybernetics, Banff Center, AB, Canada, 5-8 October 2017; IEEE: New York, NY, USA, 2017; pp. 3636-3641. [CrossRef]

22. Gomes, M.; Zeleznikow, J.; Novais, P. A Non-intrusive Approach to Measuring Trust in Opponents in a Negotiation Scenario. In Proceedings of the International Workshop on AI Approaches to the Complexity of Legal Systems, Beijing, China, 19 September 2018; Springer: Berlin/Heidelberg, Germany, 2018; pp. 528-542. [CrossRef]

23. Kling, R.; Rosenbaum, H.; Sawyer, S. Understanding and Communicating Social Informatics: A Framework for Studying and Teaching the Human Contexts of Information and Communication Technologies; Information Today: Medford, OR, USA, 2007; pp. 5-8.

24. Hyysalo, S.; Pollock, N.; Williams, R. Method Matters in the Social Study of Technology: Investigating the Biographies of Artifacts and Practices. Sci. Technol. Stud. 2019, in press.

25. Nadvornik, V. How Czech Students and Teachers use the Internet. Acta Inform. Pragensia 2013, 2, 70-78. [CrossRef]

26. Van den Bergh, J.; Behrer, M. How Cool Brands Stay Hot: Branding to Generation, Y; Kogan Page: London, UK, 2011. 
27. Savage, S. Making Sense of Generation Y: The World View of 15-25 Year Olds; Church House Publishing: London, UK, 2011.

28. Caruso, C. Understanding, Y; John Wiley \& Sons: Hoboken, NJ, USA, 2014.

29. Smola, K.W.; Sutton, C.D. Generational differences: Revisiting generational work values for the new millennium. J. Organ. Behav. 2002, 23, 363-382. [CrossRef]

30. Twenge, J.M.; Campbell, W.K.; Freeman, E.C. Generational Differences in Young Adults' Life Goals, Concern for Others, and Civic Orientation, 1966-2009. J. Personal. Soc. Psychol. 2012, 102, 1045-1062. [CrossRef]

31. Myers, K.K.; Sadaghiani, K. Millennials in the Workplace: A Communication Perspective on Millennials' Organizational Relationships and Performance. J. Bus. Psychol. 2010, 25, 225-238. [CrossRef]

32. Valentine, D.B.; Powers, T.L. Generation Y values and lifestyle segments. J. Consum. Mark. 2013, 30, 597-606. [CrossRef]

33. Smutny, Z.; Janoscik, V.; Cermak, R. Generation Y and Internet Privacy: Implication for Commercialization of Social Networking Services. In Analyzing the Strategic Role of Social Networking in Firm Growth and Productivity; Benson, V., Saridakis, G., Tuninga, R., Eds.; IGI Global: Philadelphia, PA, USA; Hershey: Derry Township, PA, USA, 2017; pp. 95-119. [CrossRef]

34. Ingen, D.J.; Freiheit, S.R.; Steinfeldt, J.A.; Moore, L.L.; Wimer, D.J.; Knutt, A.D.; Scapinello, S.; Roberts, A. Helicopter Parenting: The Effect of an Overbearing Caregiving Style on Peer Attachment and Self-Efficacy. J. Coll. Couns. 2015, 18, 7-20. [CrossRef]

35. Smutny, Z.; Dolezel, M. Social Informatics Challenges Connected with Generational Changes and the Design, Acceptance and Use of ICT. In Proceedings of the International Conference on Engineering Technologies and Computer Science (EnT), Moscow, Russia, 26-27 March 2019; IEEE: New York, NY, USA, 2019; pp. 75-79. [CrossRef]

36. Yin, R.K. Case Study Research: Design and Methods, 5th ed.; Sage: Los Angeles, CA, USA, 2017.

37. Myers, M.D. Qualitative Research in Business, 2nd ed.; Sage: London, UK, 2013; pp. 5-14.

38. Cobb-Clark, D.A.; Schurer, S. The stability of big-five personality traits. Econ. Lett. 2012, 115, 11-15. [CrossRef]

39. Watson, D.; Clark, L.A.; Tellegen, A. Development and validation of brief measures of positive and negative affect: The PANAS scales. J. Personal. Soc. Psychol. 1988, 54, 1063-1070. [CrossRef]

40. Sedlar, M. Vzt'ahy medzi zážitkom prúdenia, životnou zmysluplnost'ou a subjektívnou pohodou u študentov hudby [Relationships between Flow Experience, Life Meaningfulness and Subjective Well-being in Music Students]. Psychol. a Jeji Kontexty 2014, 5, 89-104.

41. Simkova, N.; Smutny, Z. Conceptual design of online dispute resolution in B2B relationships. In Proceedings of the 24th Interdisciplinary Information Management Talks, Podebrady, Czech Republic, 7-9 September 2016; Trauner Verlag: Linz, Austria, 2016; pp. 303-310.

42. Dorcak, P.; Pollak, F.; Szabo, S. Analysis of the Possibilities of Improving an Online Reputation of Public. In Proceedings of the 22nd Interdisciplinary Information Management Talks, Podebrady, Czech Republic, 10-12 September 2014; Trauner Verlag: Linz, Austria, 2014; pp. 275-282.

43. Falbo, T.; Peplau, L.A. Power strategies in intimate relationships. J. Personal. Soc. Psychol. 1980, 38, 618-628. [CrossRef]

44. Herring, S.C. Gender and power in online communication. In The Handbook of Language and Gender; Holmes, J., Meyerhoff, M., Eds.; Blackwell: Malden, MA, USA, 2003; pp. 202-228.

45. McKenna, K.Y.A.; Bargh, J.A. Causes and consequences of social interaction on the internet: A conceptual Framework. Media Psychol. 1999, 1, 249-269. [CrossRef]

46. Pines, A.M.; Gat, H.; Tal, Y. Gender differences in content and style of argument between couples during divorce mediation. Confl. Resolut. Q. 2002, 20, 23-50. [CrossRef]

47. Rudman, L.A.; Glick, P. Feminized management and backlash toward agentic women: The hidden costs to women of a kinder, gentler image of middle managers. J. Personal. Soc. Psychol. 1999, 77, 1004-1010. [CrossRef]

48. Helm, R.; Möller, M.; Mauroner, O.; Conrad, D. The effects of a lack of social recognition on online communication behavior. Comput. Hum. Behav. 2013, 29, 1065-1077. [CrossRef]

49. Kimbrough, A.M.; Guadagno, R.E.; Muscanell, N.L.; Dill, J. Gender differences in mediated communication: Women connect more than do men. Comput. Hum. Behav. 2013, 29, 896-900. [CrossRef] 
50. European Commission. Report from the Commission to the European Parliament and the Council on the Functioning of the European Online Dispute Resolution Platform Established under Regulation (EU) No 524/2013 on Online Dispute Resolution for Consumer Disputes. Available online: https://ec.europa.eu/info/ sites/info/files/first_report_on_the_functioning_of_the_odr_platform.pdf (accessed on 19 June 2019).

51. Gao, W. The Success and Failure of Online Dispute Resolution. Hong Kong Law J. 2017, 47, 445-474.

52. Ebner, N.; Zeleznikow, J. No Sheriff in Town: Governance for Online Dispute Resolution. Negot. J. 2016, 32, 297-323. [CrossRef]

53. Clifford, D.; Van Der Sype, Y.S. Online dispute resolution: Settling data protection disputes in a digital world of customers. Comput. Law Secur. Rev. 2016, 32, 272-285. [CrossRef]

(C) 2019 by the authors. Licensee MDPI, Basel, Switzerland. This article is an open access article distributed under the terms and conditions of the Creative Commons Attribution (CC BY) license (http://creativecommons.org/licenses/by/4.0/). 